\title{
ACEITAÇÃO E RESISTÊNCIA À EDUCAÇÃO A DISTÂNCIA: REFLEXÕES SOBRE EXPERIÊNCIAS DE FUNCIONÁRIOS DE UMA EMPRESA LOCALIZADA NA REGIÃO SUL DO BRASIL
}

\author{
Morgana Machado Tezza ${ }^{1}$
}

\begin{abstract}
RESUMO
Nesta pesquisa apresenta-se um estudo sobre a aceitação e resistência à educação a distância no contexto corporativo. Os dados empíricos foram obtidos por meio de entrevistas com funcionários de uma empresa de grande porte localizada na região norte de Santa Catarina. Os resultados indicaram que os empregados entrevistados estão mais inclinados a "aceitar" a EaD do que "resistir" a ela. Ressalta-se que, apesar de esta pesquisa apresentar apenas uma amostra do cenário de Educação Corporativa a Distância desta empresa, ela traz contribuições significativas. Contudo, enfatiza-se que, ao tratar de outro grupo de alunos ou outro tipo de curso, novas mudanças de categorias de aceitação ou de resistência poderão surgir, emergindo, assim, novos levantamentos e interpretações de dados.
\end{abstract}

Palavras-chave: Educação a distância. Educação corporativa a distância. Educação.

\footnotetext{
${ }^{1}$ Mestre, e-mail: morganatezza@yahoo.com.br
} 


\section{INTRODUÇÃO}

O advento tecnológico e a rapidez com que as mudanças ocorrem no contexto social demandam profissionais com capacidade de adaptação constante. A evolução tecnológica exige não somente o saber técnico, mas também competências comportamentais, geralmente adquiridas por meio do sistema educacional, tais como: liderança, capacidade de lidar com adversidades, pressões e trabalhar em equipes. O Brasil, com a sua amplitude geográfica e diferentes realidades regionais, tem dificuldades de acompanhar, em suas políticas educacionais, a real necessidade de desenvolvimento de competências das corporações. Segundo Portella (2005), a sincronia entre o que se aprende na escola com aquilo que o mundo corporativo exige é muito distante. No entanto, dada a importância do conhecimento acadêmico, que gera fundamentos essenciais para o desenvolvimento de competências, é mister articulá-lo às necessidades do mercado corporativo.

Nesse cenário, diante das necessidades específicas das empresas, não contempladas no sistema educacional brasileiro2, surge, no fim do século XX, o conceito de Educação Corporativa desenvolvida em Universidades Corporativas (UC), por intermédio das quais as empresas buscam suprir suas necessidades, qualificando seus funcionários naquilo em que necessitam, por meio de seus centros de treinamento.

No Brasil, os dados fornecidos pelo Anuário Brasileiro Estatístico de Educação Aberta e a Distância (ABRAEaD), indicam que, em média, $70 \%$ das empresas que investem em educação corporativa fazem uso da EaD. Outras organizações estão aprimorando seus programas rumo à virtualização, seja para se concentrarem apenas em $\mathrm{EaD}$, ou para o desenvolvimento de projetos híbridos (blended-learning).

No que tange à escolha das tecnologias, a Associação Brasileira de Educação a Distância (2010) constatou que o ambiente corporativo não faz uso consistente das mídias interativas, compostas por texto, imagem, áudio e vídeo, as quais, do ponto de vista pedagógico, ajudam a reduzir a sensação de isolamento do aluno e, além disso, contribuem com o desenvolvimento de competências, como por exemplo, a de trabalhar de forma colaborativa e cooperativa.

Uma limitação que se apresenta quanto à exploração dos potenciais das tecnologias como ferramenta de apoio aos processos de ensino e de aprendizagem encontra-se na sua aceitação entre os alunos, uma vez que é de grande importância que tais inovações sejam aceitas e efetivamente utilizadas nas organizações para, com isso, justificar o investimento a elas direcionado.

Segundo Brauer (2008) existem diversas categorias que corroboram a resistência ou a difícil inclusão de usuários em ambientes de aprendizagem virtuais. Dentre eles, podem ser citados os sistemas inadequados, a falta de capacitação e suporte aos usuários, e o perfil de usuários inadequado em relação ao curso proposto. Além disso, os alunos de

2 Nesta dissertação, considera-se que o sistema educacional refere-se à educação básica e superior. 
EaD apresentam algumas inseguranças, como a adaptação ao sistema não presencial e a ausência de interação com outros alunos em comparação ao ensino presencial (KNAPPER, 1988).

Apesar de a Associação Brasileira de Educação a Distância (2010) constatar que há uma tendência de que nos próximos anos a educação corporativa terá a possibilidade de crescer muito. Não obstante, a resistência à EaD constitui-se como um problema significativo, o que torna relevante investigá-la.

Litto e Formiga (2009) afirmam que a EaD já é um dos fortes contribuintes para as modificações metodológicas e tecnológicas que estão ocorrendo em todo o setor de educação e treinamento. Assim sendo, é ela (EaD) que dá acesso ao conhecimento e à certificação profissional a pessoas que antes não tinham a possibilidade de se aperfeiçoar devido às suas limitações de deslocamento e de adequação a horários e a locais rigorosamente definidos.

Dentre os pontos de investigação decorrentes de propostas metodológicas para EaD, destacamos, nesta pesquisa, o uso das Tecnologias de Informação e Comunicação (TIC) no ensino corporativo, as quais, segundo Santos Rosa (2009), constituem um dos campos decisivos de transformação da cultura e da educação, pois, a cada dia ganham mais espaço nas atividades cotidianas das pessoas, seja como forma de comunicação rápida e interativa, entretenimento, trabalho ou educação contínua. Pelo exposto, nesta introdução, e dada a relevância da Educação Corporativa a Distância (ECaD) no Brasil, eis a investigação sobre a aceitação e resistência à educação a distância na empresa de grande porte situada no sul do Brasil.

\section{ACEITAÇÃO E RESISTÊNCIA À EAD CORPORATIVA}

Considerando a relevância do uso da TI na Educação Corporativa a Distância (ECaD), enfatiza-se o modelo de aceitação e resistência à ECaD proposto por Brauer (2008).

Em 2008, Brauer adaptou e utilizou o modelo Teoria unificada de aceitação e uso da tecnologia (UTAUT) em sua tese de doutorado. Sua pesquisa gerou contribuições teóricas, que resultou no desenvolvimento e na validação de um modelo de estrutura teórica de resistência à ECaD, e contribuições práticas que podem subsidiar a implementação de ações gerenciais que proporcione maior eficácia à ECaD. Assim sendo, julgamos pertinente desenvolver esta pesquisa à luz dos estudos de Brauer, os quais culminam com as proposições desta pesquisa. Dessa maneira, utilizamos e adaptamos o modelo proposto por Brauer (2008), com o objetivo de compreender as principais dimensões de aceitação e resistência à Educação a Distância em uma empresa de grande porte da cidade de Jaraguá do Sul, Santa Catarina. 
A estrutura do modelo de aceitação e resistência à ECaD é composta por oito categorias de análise, sendo quatro categorias de resistência (autoeficácia, poucas competências em $\mathrm{TI}$, interatividade e comunicação interna) e quatro categorias de aceitação (expectativa de desempenho, expectativa de esforço, influência social e condições facilitadoras). De acordo com Brauer (2008), além dessas categorias, possivelmente, há outros fatores que implicam a aceitação ou a resistência à $\mathrm{ECaD}$, porém não foram aqui incluídos por não terem sido localizados no referencial bibliográfico estudado.

A seguir, uma breve descrição dos fatores de aceitação e dos fatores de resistência à ECaD, analisados nesta pesquisa.

\subsection{Resistência}

São fatores de resistência: autoeficácia, poucas competências em $\mathrm{Tl}$, interatividade e comunicação interna. Passamos à descrição de cada um deles.

\subsubsection{Autoeficácia}

A autoeficácia, segundo Galusha (1997), está centralizada no aprendizado e no aluno. Assim sendo, conhecer as peculiaridades de cada aluno colabora para que as potenciais barreiras do aprendizado sejam antecipadas e prevenidas. Este fator foi elaborado com base nos estudos de Brauer (2008), conforme os dados apresentados no Quadro 1.

Quadro 1: Fator autoeficácia

\begin{tabular}{|l|l|}
\hline \multicolumn{1}{|c|}{ Tópicos } & \multicolumn{1}{c|}{ Definição } \\
Autoeficácia & $\begin{array}{l}\text { Capacidade do aluno em aprender sozinho e em realizar o que planeja. } \\
\text { Julgamento dos indivíduos de suas capacidades de organizar e executar } \\
\text { cursos de ação requeridos para atingir alguns tipos designados de } \\
\text { desempenho. } \\
\text { Cultural }\end{array}$ \\
Procrastinação & $\begin{array}{l}\text { Ser disciplinado e ter necessidade de interação face a face. } \\
\text { relevantes. }\end{array}$ \\
\hline
\end{tabular}

Fonte: Da autora

Segundo Brauer e Albertin (2010), o fator autoeficácia pode ser considerado naquele aluno de EaD que tenha as seguintes características: ser disciplinado, não ser procrastinador, demonstrar capacidade de aprender sozinho e realizar o que planeja. 


\subsubsection{Poucas competências em TI}

Segundo Brauer $(2008,79)$, "o indivíduo que tem pouco domínio em TI possivelmente tem maior resistência aos cursos a distância". Este fator foi elaborado com base nos estudos de Brauer (2008), conforme os dados apresentados no Quadro 2.

Quadro 2: Fator poucas competência em TI

\begin{tabular}{|c|l|}
\hline \multicolumn{1}{|c|}{ Tópicos } & \multicolumn{1}{c|}{ Definição } \\
& Falta de domínio e treinamentos relacionados à TI \\
Conhecimento e experiência em TI, & são potenciais barreiras para a EaD, tanto em alunos \\
Habilidade, Atitudes favoráveis à TI. & $\begin{array}{l}\text { com escolaridade baixa até o doutorado, com pouca } \\
\text { ou vasta experiência profissional. }\end{array}$ \\
\hline
\end{tabular}

Fonte: Da autora

Mungania (2003) assegura que estratégias como capacitação em TI, com exemplos práticos, são fundamentais para se alcançar os objetivos educacionais.

\subsubsection{Interatividade}

A interatividade refere-se à participação do aluno no sistema, compartilhando conhecimento com os colegas, professores e com o próprio sistema de forma espontânea e rápida (BOFF; GIRRAFA, 2000). Esse fator foi elaborado com base nos estudos desenvolvidos por Brauer (2008), conforme apresentamos no Quadro 3.

Quadro 3: Fator interatividade

\begin{tabular}{|c|c|}
\hline Tópicos & Definição \\
\hline $\begin{array}{l}\text { Suporte aos alunos } \\
\text { - tutores }\end{array}$ & $\begin{array}{l}\text { Os tutores apontam como suporte ao aluno o atendimento, a } \\
\text { frequência, a profundidade das respostas, feedback rápido. Interagir } \\
\text { e estimular os alunos ao aprendizado. Conhecer e entender às } \\
\text { necessidades individuais de cada aluno. }\end{array}$ \\
\hline $\begin{array}{l}\text { Suporte recebido } \\
\text { - alunos }\end{array}$ & $\begin{array}{l}\text { Os alunos avaliam o suporte recebido [...] em termos do detalhamento } \\
\text { das informações a respeito do desenvolvimento do curso (atividades, } \\
\text { leituras complementares, cronogramas) da avaliação (métodos } \\
\text { e critérios de avaliação, datas e aspectos complementares como } \\
\text { possibilidade de substituição e repetição de avaliação) e da } \\
\text { intensidade da frequência de atendimento dos professores às suas } \\
\text { necessidades e questionamentos. }\end{array}$ \\
\hline
\end{tabular}


Alguns autores sugerem que se ofereçam cursos semipresenciais a fim de que tal interação ocorra efetivamente (MOORE; BENBASAT, 1991; SANTOS ROSA, 2009).

\subsubsection{Comunicação interna}

As pessoas, ao serem convidadas para fazer cursos a distância, precisam conhecer as vantagens da referida modalidade de ensino e de que forma ela pode complementar ou suprir a forma tradicional de aprender. Não existem métodos prontos e únicos para tratar as resistências à $E a D$, mas a comunicação eficaz é uma ferramenta básica e essencial para isso (DUTRA, [2010]). Santos Rosa (2009) corrobora Dutra ([2010]), informando que as diretivas do curso a distância devem ser esclarecidas no início do curso, e o processo de comunicação deve se estender ao longo do curso, de forma contínua e eficiente

Esse fator foi elaborado fundamentando-nos nos estudos desenvolvidos por Brauer (2008), conforme os dados apresentados no Quadro 4.

Quadro 4: Fator comunicação interna

\begin{tabular}{|c|l|}
\hline Tópicos & \multicolumn{1}{c|}{ Definição } \\
Comunicação & $\begin{array}{l}\text { As pessoas precisam ser informadas, conscientizadas e sensibilizadas } \\
\text { para os benefícios de determinado curso a fim de promover uma } \\
\text { maior participação dos alunos e minimizar as resistências. No } \\
\text { processo de comunicação, é fundamental que a mensagem seja } \\
\text { compreendida e que o ouvinte possa dar um retorno. }\end{array}$ \\
\hline
\end{tabular}

Fonte: Da autora

Incentivar e apoiar os empregados a realizarem cursos a distância pode ser considerado algo importante. Nesse sentido, a comunicação interna tem o papel de ouvir os empregados, transmitir informações importantes e promover o diálogo. Sem comunicação interna ou com uma comunicação interna pouco eficaz, possivelmente a resistência à ECaD seja maior (BRAUER, 2008). 


\subsection{Aceitação}

São fatores de aceitação: expectativa de desempenho, expectativa de esforço, influência social e condições facilitadoras. Passamos a descrição desses fatores.

\subsubsection{Expectativa de desempenho}

O fator expectativa de desempenho, segundo Venkatesh et al. (2003), reflete o grau em que o indivíduo acredita que a utilização do sistema possa ajudá-lo a obter ganhos de desempenho em seu trabalho. Este fator da UTAUT foi elaborado com base nas informações do Quadro 5.

Quadro 5: Fator expectativa de desempenho

\begin{tabular}{|c|c|c|}
\hline Tópicos & Definição & Teoria \\
\hline Utilidade percebida & $\begin{array}{l}\text { Grau em que um indivíduo acredita que se utilizar } \\
\text { um determinado sistema permitirá reforçar o seu } \\
\text { desempenho }\end{array}$ & $\begin{array}{l}\text { TAM, } \\
\text { TAM2 }\end{array}$ \\
\hline Motivação extrínseca & $\begin{array}{l}\text { Grau em que um indivíduo é motivado a executar uma } \\
\text { atividade em prol de sua ascensão profissional. }\end{array}$ & MM \\
\hline Ajuste ao trabalho & $\begin{array}{l}\text { Grau em que o indivíduo acredita que, a partir } \\
\text { do momento em que se usa alguma tecnologia, o } \\
\text { desempenho no trabalho melhora. }\end{array}$ & MPCU \\
\hline Vantagem relativa & $\begin{array}{l}\text { Grau em que uma inovação é percebida como uma } \\
\text { melhoria na maneira existente de fazer as atividades. }\end{array}$ & IDT \\
\hline $\begin{array}{l}\text { Expectativa } \\
\text { de resultado } \\
\text { desempenho }\end{array}$ & $\begin{array}{l}\text { Expectativas relacionadas com o resultado nos postos de } \\
\text { trabalho. }\end{array}$ & SCT \\
\hline $\begin{array}{l}\text { Expectativa de } \\
\text { resultado - pessoal }\end{array}$ & $\begin{array}{l}\text { Consequência do desempenho individual e sentimento } \\
\text { de realização. }\end{array}$ & SCT \\
\hline
\end{tabular}

Fonte: Adaptado de Venkatesh et al. (2003) 


\subsubsection{Expectativa de esforço}

O fator expectativa de esforço, segundo Venkatesh et al. (2003), reflete o grau facilidade de uso do sistema. Esse fator da UTAUT foi elaborado com base no que se apresenta no Quadro 6.

Quadro 6: Fator expectativa de esforço

\begin{tabular}{|l|l|l|}
\hline \multicolumn{1}{|c|}{ Tópicos } & \multicolumn{1}{c|}{ Definição } & \multicolumn{1}{c|}{ Teoria } \\
$\begin{array}{l}\text { Facilidade de } \\
\text { uso percebido }\end{array}$ & $\begin{array}{l}\text { Grau de percepção de um indivíduo em relação à facilidade } \\
\text { de uso percebida. } \\
\text { Relacionada diretamente ao grau em que a inovação é } \\
\text { percebida e complicada de ser entendida. }\end{array}$ & $\begin{array}{l}\text { TAM, } \\
\text { TAM2 }\end{array}$ \\
$\begin{array}{l}\text { Facilidade de } \\
\text { uso }\end{array}$ & $\begin{array}{l}\text { Relacionada diretamente ao grau em que o indivíduo } \\
\text { percebe que utilizar um sistema novo nem sempre é difícil. }\end{array}$ & IDT \\
\hline
\end{tabular}

Fonte: Adaptado de Venkatesh et al. (2003)

Dessa forma, seguindo os argumentos dos autores, consideramos que o fator expectativa de esforço tenha influência sobre a resistência à EaD na EC.

\subsubsection{Influência social}

A influência social, segundo Venkatesh et al. (2003), consiste no grau de aceitação do indivíduo das informações que recebe de pessoas em quem confia, as quais podem conduzi-lo ou não ao uso de um Sistema de Informação. Esse fator da UTAUT foi elaborado com base nas informações apresentadas no Quadro 7.

Quadro 7: Fator influência social

\begin{tabular}{|l|l|l|}
\hline \multicolumn{1}{|c|}{ Tópicos } & \multicolumn{1}{|c|}{ Definição } & \multicolumn{1}{|c|}{ Teoria } \\
Norma & $\begin{array}{l}\text { Grau de convencimento do indivíduo sobre a opinião de outras } \\
\text { pessoas, que são importantes para ele, sobre realizar ou não } \\
\text { cursos a distância. }\end{array}$ & $\begin{array}{l}\text { TAM, TAM2, } \\
\text { TPD/ DTPB }\end{array}$ \\
Fatores & $\begin{array}{l}\text { Internalização, pelo indivíduo, da cultura subjetiva de um } \\
\text { grupo de referências e acordos específicos interpessoais que o } \\
\text { Sociais }\end{array}$ & MPCU \\
indivíduo tem com outros em situações sociais. & $\begin{array}{l}\text { Utilização dos sistemas melhora a imagem do indivíduo nos } \\
\text { Imagem }\end{array}$ & IDT \\
\hline
\end{tabular}


Assim sendo, percebe-se que o fator influência social pode ser determinante na aceitação do usuário em relação à EaD na EC. Se a pessoa ou o grupo nos quais os indivíduos confiam demonstrarem-se receptivos à EaD, sua aceitação será maior por parte dos usuários. Caso contrário, a resistência persistirá (BRAUER; ALBERTIN, 2010).

\subsubsection{Condições facilitadoras}

O fator condições facilitadoras, conforme Venkatesh et al. (2003), é definido pelo grau em que um indivíduo confia que há uma infraestrutura organizacional e técnica apropriada para apoiar o uso do sistema. Esse fator da UTAUT foi elaborado tendo por base fatores conforme apresentamos no Quadro 8.

Quadro 8: Fator condições facilitadoras

\begin{tabular}{|c|c|c|}
\hline Tópicos & Definição & Teoria \\
\hline $\begin{array}{l}\text { Controle percebido } \\
\text { do comportamento }\end{array}$ & $\begin{array}{l}\text { Reflete percepções dos constrangimentos } \\
\text { internos e externos sobre o comportamento, } \\
\text { englobando a autoeficácia, e condições dos } \\
\text { recursos e de tecnologia. }\end{array}$ & DTPB \\
\hline $\begin{array}{l}\text { Condições } \\
\text { facilitadoras }\end{array}$ & $\begin{array}{l}\text { Fatores de infraestrutura (tecnológica, } \\
\text { espacial, temporal e pedagógica) necessários } \\
\text { para a realização do curso. }\end{array}$ & MPCU \\
\hline Compatibilidade & $\begin{array}{l}\text { Grau em que uma inovação é percebida como } \\
\text { sendo condizente com os valores existentes, } \\
\text { as necessidades, as experiências passadas e } \\
\text { os potenciais adotados. }\end{array}$ & IDT \\
\hline
\end{tabular}

Fonte: Adaptado de Venkatesh et al. (2003)

Com o objetivo de obter melhor produtividade, as organizações investem muito em TI, mas, para que isso ocorra, as inovações precisam ser aceitas e efetivamente utilizadas nas organizações (VENKATESH et al., 2003). Uma das barreiras encontradas em TI está justamente na sua aceitação entre os usuários finais (POZZEBON; PETRINI, 2002). 


\section{METODOLOGIA}

Com base nos objetivos da pesquisa, busca-se compreender as principais dimensões de aceitação e resistência à Educação a Distância em uma empresa de grande porte da cidade de Jaraguá do Sul. Esta pesquisa teve caráter qualitativo, justificado pela visão de Martins (2006), uma vez que se caracteriza pela descrição, compreensão e interpretação de fatos e fenômenos. Embora as condições para a utilização da pesquisa qualitativa sejam comuns, nem todas são utilizadas da mesma forma. Após o entendimento da aplicação de cada uma delas, optamos pelo método de investigação caracterizado como estudo de caso, levando-se em conta suas peculiaridades, objetivos e pela facilidade de acesso às informações. Yin (2005) afirma que a essência de um estudo de caso é tentar esclarecer uma decisão ou um conjunto de decisões. Ou seja, deixar evidente o motivo pelo qual as decisões foram tomadas, como foram implementadas e com quais resultados.

O material empírico foi composto por fontes primárias, por intermédio de entrevistas em profundidade. Para Alves-Mazzotti e Gewandsznajder (2002, p. 168), "as entrevistas qualitativas devem ser pouco estruturadas, sem uma ordem rígida, e parecer mais como se fosse uma conversa do que propriamente uma entrevista". Godoi e Mattos (2006, p. 317) explicam que o método de entrevistas em profundidade "serve para desvelar emoções, sentimentos e subjetividade", e ressaltam que "a arte de perguntar e escutar afeta, em diversos níveis, as necessidades psicológicas dos indivíduos".

Para a coleta de dados, elaboramos um roteiro semiestruturado, composto de tópicos adaptados com base no modelo de Brauer (2008), que apresenta as categorias de análise da pesquisa, suas unidades de significado e os tópicos do roteiro.

A população entrevistada foi composta por um gerente, um chefe, um chefe departamento e cinco auxiliares, todos funcionários de uma empresa de grande porte situada na região Sul do Brasil. O sujeito da pesquisa representou um todo significativo que possibilitou identificar repetições sistêmicas e consistentes.

A amostra representou um todo significativo que possibilitou identificar repetições sistêmicas e consistentes. A unidade amostral para esta pesquisa foram os funcionários da empresa participante deste estudo, sendo: um gerente, um chefe de departamento e cinco auxiliares. A escolha foi feita independentemente do sexo ou da idade, e sim que o indivíduo participante tivesse realizado, no mínimo, um curso a distância patrocinado pela empresa. A quantidade de entrevistados foi estabelecida por saturação amostral, ou seja, as entrevistas finalizaram quando as respostas começaram a se repetir.

Silva, Godoi e Bandeira-Demello (2006) comenta que a etapa de transcrição das entrevistas é uma das etapas determinantes da pesquisa. É o processo de análise compreensiva interpretativa dos dados, que procura delimitar passos para compreender o fenômeno em estudo. Assim, após as entrevistas, realizou-se a leitura, codificação, classificação dos temas, agrupamento dos relatos das entrevistas por temas, e, finalmente, a análise e a interpretação das informações coletadas. 


\section{REFLEXÕES SOBRE AS EXPERIÊNCIAS DE FUNCIONÁRIOS EM UM CURSO A DISTÂNCIA}

Neste tópico apresentam-se uma análise das experiências dos funcionários no curso supracitado, que foi organizada pelas categorias resistência e aceitação e seus respectivos temas.

\subsection{Resistência}

\subsubsection{Autoeficácia}

Brauer (2008) define autoeficácia como a capacidade de uma pessoa aprender sozinha e de realizar o que planeja. Alunos com tais características aceitam a EaD com maior facilidade. Já os que não as possuem são conduzidos à resistência à EaD.

Assim, conhecer as peculiaridades de cada aluno colabora para que as potenciais barreiras do aprendizado sejam antecipadas e prevenidas. Para os alunos entrevistados, há um consenso sobre a importância do estudo em grupo. No entanto, segundo eles, não foi evidenciada a necessidade de encontros presenciais para concretizar os estudos. Os estudos individuais são mais propícios para conteúdos de áreas exatas, por exemplo. Porém, quando se trata de temas que podem conduzir a debates, reflexões ou opiniões diversificadas, a aprendizagem colaborativa torna-se mais eficiente. De acordo com os entrevistados, para se obter um bom aproveitamento em um curso a distância, é necessário inserir nas atividades cotidianas, horários destinados para a realização dos estudos, e com isso evitar a indisciplina.

Raffoni (2006) comenta que o gerenciamento do tempo é sinônimo de disciplina, ou seja, habilidade de pôr em prática o que foi planejado. No Quadro 9, apresentamos o resultado que possibilita identificar os temas que conferem aceitação ou resistência à EaD, referentes a categoria autoeficácia.

Quadro 9: Resultado da categoria autoeficácia

\begin{tabular}{|l|l|}
\hline \multicolumn{1}{|c|}{ Tema } & Resultado \\
\hline Necessidade de interação presencial nas aulas ou no estudo & Aceitação \\
Indisciplina e dificuldades com o gerenciamento do tempo & Resistência \\
Procrastinação & Resistência \\
\hline
\end{tabular}

Fonte: Da autora 


\subsubsection{Poucas competências em TI}

Segundo Brauer (2008), aquele indivíduo que não domina as tecnologias da informação tem maiores dificuldades e resistências para com os cursos a distância. Mungania (2003) enfatiza que a falta de habilidade e conhecimento na área de TI são potenciais barreiras à EaD, independentemente de escolaridade e experiência profissional. Com base nas entrevistas, infere-se que a pessoa que tem pouco conhecimento e experiência em TI possivelmente tem maior resistência e, por outro lado, aquela que tem certo conhecimento tem maior aceitação aos cursos a distância. Dos sete entrevistados, dois disseram ter pouco conhecimento e experiência em $\mathrm{TI}$, já os demais possuem bom conhecimento e experiência. No Quadro 10, apresenta-se, com base na análise dos dados obtidos por meio das entrevistas, o resultado que possibilita identificar os temas que conferem aceitação ou resistência à EaD, referentes a categoria poucas competências em TI:

Quadro 10: Resultado da categoria Poucas competências em TI

\begin{tabular}{|l|l|}
\hline Temas & Resultado \\
Conhecimento e experiência em TI & Aceitação \\
Habilidade em TI & Aceitação \\
\hline Atitudes favoráveis à TI & Aceitação \\
\hline
\end{tabular}

Fonte: Da autora

\subsubsection{Interatividade}

Santos Rosa (2009) lembra que, na EaD, a interação entre os participantes de um curso (professores, estudantes e equipe técnica) é essencial. Pois trata-se da ação recíproca entre os participantes, a qual ocorrerá em uma dimensão ou domínio virtual que dependerá das condições promovidas, das ações pedagógicas e dos recursos tecnológicos utilizados.

Pelas asserções dos entrevistados, evidencia-se a falta da efetivação desta categoria no curso. Por isso, dada a falta de efetivação da interação, não há evidências de que este tema remete à aceitação ou à resistência dos entrevistados à EaD. No entanto, esta categoria pode ser fundamental em cursos desta natureza.

\subsubsection{Comunicação interna}

Fica claro nas entrevistas a falta de comunicação interna entre a equipe técnica e de gestão do curso e os alunos. Conforme Santos Rosa (2009), as diretivas do curso a distância devem ser esclarecidas no início do curso, e o processo de comunicação deve se estender ao longo do curso, de forma contínua e eficiente, pois essas diretivas conduzirão o aluno para realizar o curso com melhor organização e aproveitamento. 
Os entrevistados consideram que a divulgação dos cursos a distância não alcançou todos os funcionários, que o cronograma de trabalho para a realização dos cursos não foi divulgado e que não houve uma comunicação ou aviso prévio sobre o curso. Esse fato pode influenciar na falta de planejamento desses alunos e, com isso, criar frustrações e consequentemente desistência e, finalmente, corroborar a resistência à EaD.

\subsection{Aceitação}

\subsubsection{Expectativa de desempenho}

Para Venkatesh et al. (2003), a expectativa de desempenho está relacionada ao quanto o sujeito acredita que aquele curso o ajudará a melhorar seu desempenho no trabalho. Assim, de acordo com o resultado das entrevistas, todos os entrevistados consideram que a EaD contribui com o desempenho de suas respectivas atividades profissionais, dadas as possibilidades de realizar cursos sem horário e local fixo.

\subsubsection{Expectativa de esforço}

Rogers (1995) considera que a TI é uma inovação e, por isso, afirma que a complexidade de uma ferramenta contribui para a facilidade ou não de acesso e navegação no ambiente virtual de ensino aprendizagem do curso. Quanto mais complexa for uma TI, mais difícil será a sua compreensão e a sua utilização, levando o indivíduo a demandar grande esforço para apreender os conteúdos transmitidos.

Nesta pesquisa constata-se que, apesar de o ambiente virtual de aprendizagem dispor de diversos recursos aos participantes dos cursos, foram utilizados apenas recursos básicos e necessários à transmissão dos conteúdos. Tais recursos não demandavam grandes esforços para o seu uso, em razão da fácil navegabilidade.

\subsubsection{Influência social}

Lapointe e Rivard (2005) sugerem que a resistência à TI pode aumentar gradualmente nos sujeitos de acordo com a frequência que eles expressarem isso uns aos outros. Inferese a maioria dos entrevistados fez o curso por indicação do seu superior hierárquico e não por escolha própria.

Assim, houve uma obrigatoriedade e não um interesse explícito em fazê-lo. Pelo exposto, conclui-se que o principal motivo dos entrevistados em realizar este curso deveu-se à obrigatoriedade, ou seja, não existiu espaço para aceitação ou rejeição, e sim para cumprir uma determinação. Outra constatação é a de que não há incentivo dos colegas e dos superiores para a realização de cursos desta natureza. 
Assim, os dados apontaram uma nova categoria, que não será tratada nesta pesquisa, que é a obrigatoriedade e, diante disso, a participação dos alunos não sofreu influência social.

\subsubsection{Condições facilitadoras}

De acordo com os dados levantados, os entrevistados manifestaram que não houve problemas relacionados às tecnologias utilizadas. Sendo assim, evidencia-se que há conhecimento e conscientização sobre a importância da robustez das tecnologias utilizadas em cursos que utilizam tais recursos como principal meio de ensino. Segundo Santos Rosa (2009), cursos a distância devem ser apoiados por monitores e tutores, para com isso melhorar a qualidade. Porém, os entrevistados não utilizaram estes apoios. Assim, constata-se que os cursos foram realizados mesmo sem tais apoios e que estes não indicam ser uma categoria de resistência à EaD, e se aproxima mais à aceitação, pelo fato de não terem sido importantes, para os participantes. No Quadro 11 , o resultado que possibilita identificar os temas que conferem aceitação ou resistência à $\mathrm{EaD}$, referentes a categoria condições facilitadoras.

Quadro 11: Resultado da categoria condições facilitadoras

\begin{tabular}{|l|l|}
\hline Temas & Resultado \\
Condições técnicas facilitadoras & Aceitação \\
Condições organizacionais facilitadoras & Aceitação \\
\hline
\end{tabular}

Fonte: Da autora

\section{CONSIDERAÇÕES FINAIS}

A partir deste estudo, possibilitou-se identificar as categorias de resistência e de aceitação à ECaD da empresa de grande porte da região sul do Brasil, assim,espera-se contribuir com a definição de estratégias de gestão, pedagógica e de tecnologias de seus cursos a distância realizados nesta empresa.

De acordo com os dados empíricos, a aferição de que os entrevistados: adotariam a $\mathrm{EaD}$, porém consideraram que os cursos realizados por eles não agregaram valor à sua profissão; consideram pertinente adaptar cursos presenciais para EaD.

No entanto, apresentaram recomendações para a $\mathrm{EaD}$, por exemplo, a elaboração de metodologias fortalecidas pela interação entre os participantes do curso (tutor e aluno); consideram pertinente adotar a EaD corporativa, mas apresentam alguns cuidados que devem ser adotados, tais como: identificar o perfil dos alunos, o tipo de curso 
(conteúdo) e a quantidade de alunos. Para eles a EaD torna-se mais relevante nessas condições; as vantagens da EaD foram sintetizadas em: possibilidade de atender a vários alunos num mesmo curso, a flexibilidade de local e horário, a possibilidade de disseminar conhecimentos entre os participantes; e a redução de custo; as desvantagens apresentadas sobre a EaD foram: falta de apoio para tirar dúvidas sobre o conteúdo; falta de interação; e falta de disciplina dos alunos.

É importante ressaltar que, apesar de esta pesquisa apresentar apenas uma amostra do cenário de ECaD desta empresa, ela traz contribuições significativas.

Contudo,é importante enfatizar que, ao tratar de outro grupo de alunos ou outro tipo de curso, novas mudanças de categorias de aceitação ou de resistência poderão surgir, emergindo, assim, novos levantamentos e interpretações de dados. Assim, corroborando Santos Rosa (2009) ao estabelecer um curso a distância, é necessário conhecer suas potencialidades e possibilidades para que atenda às expectativas e às aspirações dos entes envolvidos, o que inclui os proponentes e os participantes.

\title{
ACCEPTANCE AND RESISTANCE TO DISTANCE EDUCATION: REFLECTIONS ON EXPERIENCES OF EMPLOYEES OF A COMPANY LOCATED IN SOUTHERN BRAZIL
}

\begin{abstract}
This research presents a study on the acceptance and resistance to Distance Education (DE) in the corporate context. Empirical data were obtained through interviews with employees of a large company located in the northern region of Santa Catarina. The results indicated that the employees that were interviewed are more inclined to "accept" the DE's as opposed to "resist" to it. It should be noted that although this study presents only a sample scenario of Corporate Education at Distance of this company, it brings significant contributions. However, it is emphasized that, in dealing with another group of students or other type of course, new changes of categories of acceptance or resistance may appear, emerging, thus, new surveys and interpretations of data.
\end{abstract}

Keywords: Distance. Corporate Education at Distance. Education. 


\section{REFERENCIAS}

ALVES-MAZZOTTI, A. J.; GEWANDSZNAJDER, F. O Método nas ciências naturais e sociais - pesquisa quantitativa e qualitativa. São Paulo: Pioneira Thomsom Learning, 2002.

ASSOCIAÇÃO BRASILEIRA DE EDUCAÇÃO A DISTÂNCIA (Org.). Censo EAD.br: relatório analítico da aprendizagem a distância no Brasil. São Paulo, SP: Pearson, 2010.

BOFF, E. ; GIRRAFA, L. M. M. Construindo um ambiente de ensino-aprendizagem cooperativo: uma experiência interdisciplinar. In: SIMPÓSIO BRASILEIRO DE INFORMÁTICA NA EDUCAÇÃO (SBIE 2000), 11., 2000, Maceió. Anais... Maceió, 2000.

BRAUER, M. Resistência à Educação a Distância na Educação Corporativa. 2008. 188 f. Tese (Doutorado em Administração de Empresas) - Programa de Mestrado Acadêmico e Doutorado em Administração de Empresas da Fundação Getúlio Vargas, São Paulo, 2008.

BRAUER, M.; ALBERTIN, A.L. Resistência à educação a distância na educação corporativa. In: ENCONTRO ANUAL DA ASSOCIAÇÃO NACIONAL DE PROGRAMAS DE PÓS-GRADUAÇÃO EM ADMINISTRAÇÃO, 34. 2010, Rio de Janeiro. Anais... Rio de Janeiro, 2010. p.1-16.

DUTRA, D. O desafio do e-learning: vencer as barreiras comportamentais. Revista RH Magazine, Portugal, [2010]. Disponível em: <http://www.always.com.br/site2005/ endo_clip04.html>. Acesso em: 20 fev. 2010.

GALUSHA, J. M. Barriers to Learning in Distance Education. Interpersonal Computing and Technology: an electronic journal for the 21st century. 1997. Disponível em: <http:// www.infrastruction.com/barriers.htm>. Acesso em: 10 nov. 2010.

GODOI, C. K.; MATTOS, P. L. C. L. Entrevista qualitativa: instrumento de pesquisa e evento dialógico. In: GODOI, C. K.; BANDEIRA-DE-MELLO, R; SILVA, A. B. (Org.) Pesquisa qualitativa em estudos organizacionais: paradigmas, estratégias e métodos. São Paulo: Saraiva, 2006, p. 305-316.

KNAPPER, C. K. Lifelong learning and distance education. American Journal of Distance Education, v. 2, n. 1, p. 63-72, 1988.

LAPOINTE, L.; RIVARD, S. A multilevel model of resistance to information technology implementation. MIS Quarterly, v. 29, n. 3, p. 461-469, 2005.

LITTO, F. M.; FORMIGA, Marcos (Org.). Educação a distância: o estado da arte. São Paulo, SP: Pearson, 2009.

MARTINS, G. A. Estudo de caso: uma estratégia de pesquisa. São Paulo: Atlas, 2006.

MOORE, G.; BENBASAT, I. Development of an instrument to measure the perceptions of adopting and information technology innovation. Information Systems Research, v.2, n. 3, p. 192-22, 1991. 
MUNGANIA, P. The seven e-learning barriers facing employees. [S.I.: s.n.], 2003. Disponível em: <http://www.masie.com/researchgrants/2003/Mungania_Final_Report. pdf>. Acesso em: 10 nov. 2010.

PORTELLA, E. Educação, comunicação, saber. In: BAYMA, Fátima (Org.). Educação corporativa: desenvolvendo e gerenciando competências. São Paulo: Pearson Prentice Hall/Fundação Getúlio Vargas, 2005. p. 1-288.

POZZEBON, M.; PETRINI, M. Impactos da tecnologia da informação sobre as organizações: desvendando o paradoxo da produtividade. In: CONGRESSO DE ADMINISTRAÇÃO COPPEAD, 9., 2002, Rio de Janeiro. Anais... Rio de Janeiro: COPPEAD/UFRJ, 2002.

RAFFONI, M. Managing time. Cambridge: Harvard Business School Press, 2006.

ROGERS, E. M. Diffusion of innovations. New York: Free Press, 1995.

SANTOS ROSA, S. Possibilidades dos processos e método no ensino a distância: um estudo de caso de um curso de modelagem. 2009. 184 f. Dissertação (Mestrado em Educação) - Pós-Graduação em Educação, Universidade Regional de Blumenau, Blumenau, 2009.

SILVA, A. B. da; GODOI, C. K.; BANDEIRA-DEMELLO, R. Pesquisa qualitativa em estudos organizacionais: paradigmas, estratégias e métodos. São Paulo, SP: Saraiva, 2006. 460 p.

VENKATESH, V. et al. User acceptance of information technology: toward a unified view. MIS Quarterly, v. 27, n. 3, p. 425-478, 2003.

YIN, R. K. Estudo de caso: planejamento e métodos. Porto Alegre: Bookman, 2005.

\section{SOBRE A AUTORA}

\begin{tabular}{|l|l|} 
Graduação em Ciências da Computação pela Universidade do Sul de Santa \\
Catarina (1999), graduação em Administração em Marketing pelo Centro \\
Universitário de Jaraguá do Sul (2004), graduação em Formação Pedagógica \\
para Formadores de pela Universidade do Sul de Santa Catarina (2005), \\
Especialização Latu Sensu pelo Instituto de Pós Graduação em Gerenciamento \\
de marketing (2005) e mestrado em Administração pela Universidade do Vale \\
do Itajaí (2011). Atualmente é consultora, coordenadora da área de educação \\
a distância no SENAlsc unidade Jaraguá do Sul. Tem experiência em coordenar, \\
gerenciar projetos, desenvolver recursos didáticos tanto para materiais \\
impressos e online. Atua fortemente também na área de comercial desta \\
Machanana Tezza
\end{tabular}


Anexo A: Roteiro da entrevista

\begin{tabular}{|c|c|c|}
\hline Categorias & $\begin{array}{l}\text { Unidades de } \\
\text { significado }\end{array}$ & Tópicos \\
\hline Autoeficácia & $\begin{array}{l}\text { Capacidade } \\
\text { do funcionário } \\
\text { de aprender } \\
\text { sozinho e de } \\
\text { realizar o que } \\
\text { planeja }\end{array}$ & $\begin{array}{l}\text { Necessidade de interação presencial nas aulas ou } \\
\text { no estudo } \\
\text { Preferência na forma de estudar: sozinho ou com } \\
\text { outras pessoas } \\
\text { Forma de estudo mais produtiva: sozinho ou com } \\
\text { outros } \\
\text { Indisciplina e dificuldades com o gerenciamento } \\
\text { do tempo } \\
\text { Forma de priorizar as suas atividades } \\
\text { Disciplina e ordem para estudar } \\
\text { Procrastinação } \\
\text { Forma de priorizar as atividades } \\
\text { Incidência da procrastinação nas atividades diárias }\end{array}$ \\
\hline $\begin{array}{l}\text { Poucas } \\
\text { competências } \\
\text { em TI }\end{array}$ & $\begin{array}{l}\text { Conhecimentos, } \\
\text { experiências, } \\
\text { habilidades e } \\
\text { atitudes de um } \\
\text { funcionário em } \\
\text { relação à TI }\end{array}$ & $\begin{array}{l}\text { Conhecimento e experiência em TI } \\
\text { Experiência e contato com as ferramentas } \\
\text { disponíveis na internet } \\
\text { Dificuldades e facilidades com os softwares/ } \\
\text { hardware do seu computador } \\
\text { Habilidade em TI } \\
\text { Interesse e frequência na utilização do } \\
\text { computador } \\
\text { Atitudes favoráveis à TI } \\
\text { Importância dada à informática na vida pessoal e } \\
\text { profissional } \\
\text { Forma de coleta de informações atualizadas } \\
\text { Sistema utilizado para obter informações sobre } \\
\text { produtos e serviços para compará-los }\end{array}$ \\
\hline $\begin{array}{l}\text { Expectativa de } \\
\text { desempenho }\end{array}$ & $\begin{array}{l}\text { Estudar a } \\
\text { distância vai } \\
\text { ajudá-lo a } \\
\text { atingir ganhos } \\
\text { profissionais }\end{array}$ & $\begin{array}{l}\text { Expectativa de desempenho (adaptação da } \\
\text { UTAUT) } \\
\text { Percepção do EaD para o aprimoramento do seu } \\
\text { trabalho } \\
\text { Experiências com o EaD para a melhoria da } \\
\text { qualidade no seu trabalho } \\
\text { Resultado do EaD no desenvolvimento e } \\
\text { crescimento na carreira }\end{array}$ \\
\hline
\end{tabular}




\begin{tabular}{|c|c|c|}
\hline Categorias & $\begin{array}{l}\text { Unidades de } \\
\text { significado }\end{array}$ & Tópicos \\
\hline $\begin{array}{l}\text { Expectativa } \\
\text { de esforço }\end{array}$ & $\begin{array}{l}\text { Facilidade } \\
\text { associada ao } \\
\text { uso do sistema }\end{array}$ & $\begin{array}{l}\text { Facilidade de uso percebida (adaptação da } \\
\text { UTAUT) e Complexidade } \\
\text { Percepção do ambiente virtual de aprendizagem } \\
\text { utilizado } \\
\text { Percepção sobre o sistema de EaD } \\
\text { Experiências em relação à utilização do sistema } \\
\text { EaD }\end{array}$ \\
\hline $\begin{array}{l}\text { Influência } \\
\text { social }\end{array}$ & $\begin{array}{l}\text { Influência } \\
\text { recebida por } \\
\text { outras pessoas }\end{array}$ & $\begin{array}{l}\text { Influência Social } \\
\text { Preferência dos colegas e superiores quanto à } \\
\text { utilização dos cursos de EaD na influência de sua } \\
\text { participação } \\
\text { Influência recebida na realização dos cursos EaD } \\
\text { pelo superior } \\
\text { Influência recebida na realização dos cursos EaD } \\
\text { pela empresa }\end{array}$ \\
\hline $\begin{array}{l}\text { Condições } \\
\text { facilitadoras }\end{array}$ & $\begin{array}{l}\text { Infraestrutura } \\
\text { organizacional } \\
\text { e técnica para } \\
\text { suportar o uso } \\
\text { do sistema }\end{array}$ & $\begin{array}{l}\text { Condições Técnicas Facilitadoras (adaptação da } \\
\text { UTAUT) } \\
\text { Administração e resolução dos problemas no uso } \\
\text { das ferramentas de EaD } \\
\text { Recursos necessários para usar o sistema de EaD } \\
\text { Percepção acerca do funcionamento do sistema de } \\
\text { EaD } \\
\text { Percepção quanto ao acompanhamento técnico do } \\
\text { sistema EaD } \\
\text { Condições Organizacionais Facilitadoras } \\
\text { (adaptação da UTAUT) } \\
\text { Percepção quanto ao monitoramento das } \\
\text { atividades realizadas no sistema EaD } \\
\text { Percepção quanto à tutoria para a realização das } \\
\text { atividades realizadas no sistema EaD } \\
\text { Motivações para participação nos cursos de EaD }\end{array}$ \\
\hline
\end{tabular}




\begin{tabular}{|c|c|c|}
\hline Categorias & $\begin{array}{l}\text { Unidades de } \\
\text { significado }\end{array}$ & Tópicos \\
\hline Interatividade & $\begin{array}{l}\text { Interatividade e } \\
\text { tempestividade } \\
\text { entre o } \\
\text { funcionário/ } \\
\text { aluno com o } \\
\text { tutor ou com } \\
\text { outros alunos }\end{array}$ & $\begin{array}{l}\text { Interatividade } \\
\text { Percepção acerca da integração entre colegas de } \\
\text { turma nos cursos de EaD } \\
\text { Percepção acerca dos incentivos que os alunos } \\
\text { receberam do professor nos cursos de EaD } \\
\text { Grau de interatividade entre tutor e aluno no } \\
\text { saneamento de dúvidas } \\
\text { Grau de interatividade entre monitor e aluno no } \\
\text { saneamento de dúvidas } \\
\text { Feedbacks recebidos da monitoria e tutoria }\end{array}$ \\
\hline $\begin{array}{l}\text { Comunicação } \\
\text { interna }\end{array}$ & $\begin{array}{l}\text { Preparação ou } \\
\text { comunicação } \\
\text { prévia e } \\
\text { durante o curso } \\
\text { virtual }\end{array}$ & $\begin{array}{l}\text { Comunicação interna } \\
\text { Percepção acerca das informações passadas } \\
\text { antecipadamente sobre os cursos de EaD } \\
\text { oferecidos na empresa } \\
\text { Motivos que influenciaram a decisão sobre a } \\
\text { participação em cursos em EaD } \\
\text { Percepção acerca do cronograma de trabalho para } \\
\text { a realização do curso em EaD } \\
\text { Percepção acerca do veículo de comunicação } \\
\text { usado entre os alunos virtuais e os responsáveis } \\
\text { pelo EaD } \\
\text { Percepção acerca da divulgação dos cursos de EaD } \\
\text { na sua empresa } \\
\text { Meios de comunicação eficazes na realização dos } \\
\text { cursos em EaD } \\
\text { Treinamento Adequado } \\
\text { Satisfação em relação à qualidade das informações } \\
\text { recebidas para o acesso ao ambiente virtual e a } \\
\text { realização das atividades }\end{array}$ \\
\hline
\end{tabular}




\begin{tabular}{|c|c|c|}
\hline Categorias & $\begin{array}{c}\text { Unidades de } \\
\text { significado }\end{array}$ & Tópicos \\
\hline $\begin{array}{l}\text { Resistência } \\
\text { à EaD na EC }\end{array}$ & $\begin{array}{l}\text { Resistência } \\
\text { à EAD }\end{array}$ & $\begin{array}{l}\text { Resistência à TI } \\
\text { Satisfação em relação aos cursos de EaD já } \\
\text { realizados para participar de outros cursos } \\
\text { Recomendações aos colegas, parente e amigos } \\
\text { acerca dos cursos em EaD } \\
\text { Percepção quanto à didática dos cursos em EaD e } \\
\text { dos presenciais } \\
\text { Satisfação quanto à metodologia dos cursos em } \\
\text { EaD } \\
\text { Percepção acerca do EaD corporativo } \\
\text { Percepção acerca de cursos presenciais se } \\
\text { tornarem cursos EaD } \\
\text { Vantagens e desvantagens na EAD }\end{array}$ \\
\hline
\end{tabular}

